\title{
Serum adiponectin as a predictor of laboratory response to anti-TNF- $\alpha$ therapy in rheumatoid arthritis
}

\author{
DOROTA SIKORSKA ${ }^{1}$, RAFAŁ RUTKOWSKI ${ }^{2}$ JOANNA ŁUCZAK ${ }^{2}$, WŁODZIMIERZ SAMBORSKI ${ }^{1}$, \\ JANUSZ WITOWSKI
}

'Department of Rheumatology and Rehabilitation, Poznan University of Medical Sciences, Poznan, Poland

${ }^{2}$ Department of Pathophysiology, Poznan University of Medical Sciences, Poznan, Poland

\begin{abstract}
Introduction: While adiponectin is typically viewed as an anti-inflammatory mediator, such an activity of adiponectin in rheumatoid arthritis $(R A)$ is not so obvious. In the present study we examined whether serum levels of adiponectin reflect the clinical phenotype of RA patients and/or correlate with severity of the disease and the response to anti-TNF- $\alpha$ therapy.

Material and methods: Twenty-one female RA patients qualified to receive anti-TNF- $\alpha$ treatment were prospectively assessed before and after 12 weeks of therapy. Patients underwent full clinical and biochemical assessment. Disease activity was assessed by the Modified Disease Activity Scores (DAS28). Serum concentrations of adiponectin were measured with an immunoassay. The individuals were divided into two subgroups according to whether their baseline serum adiponectin was below or above the median value. The subgroups did not differ in basic demographic, anthropometric, and clinical parameters.

Results: Anti-TNF- $\alpha$ treatment resulted in a significant clinical (DAS28) improvement in patients from both subgroups, but no significant differences between basal and post-treatment serum adiponectin concentrations were observed. However, patients with higher baseline adiponectin experienced a significant and more pronounced improvement in laboratory parameters of inflammation (ESR, CRP, neutrophil count, neutrophil-to-lymphocyte ratio).

Conclusions: It is possible that adiponectin exerts systemic anti-inflammatory effects independently of the local activity of $R A$.
\end{abstract}

Key words: rheumatoid arthritis, inflammation, adiponectin, adipocytokines, anti-TNF- $\alpha$ treatment.

(Centr Eur J Immunol 2018; 43 (3): 289-294)

\section{Introduction}

It is now evident that adipose tissue-derived adipokines may critically modulate inflammatory responses in various tissues and organs [1]. These include the cartilage and the synovium of rheumatoid arthritis (RA) patients [1-4]. Adiponectin is an abundant adipokine viewed typically as an anti-inflammatory mediator. However, adiponectin activities may go beyond this paradigm, given the complexity of its isoforms, receptors, and signal transduction pathways $[2,5,6]$. While the role of adiponectin in metabolic syndrome appears to be clearly anti-inflammatory [7], it may not be the same in RA [5, 6]. In vitro studies with chondrocytes and synovial fibroblasts have shown that adiponectin can induce pro-inflammatory cytokines, chemokines, and matrix proteases in these cells $[8,9]$. Thus, the systemic role of adiponectin may be different from that being played locally in the inflamed synovium [10].

The pattern of changes in serum adiponectin that occur (if any) in RA is not clear [5, 6]. Some studies reported increased levels of adiponectin in RA [5, 6] and their correlation with clinical activity of the disease $[11,12]$. However, other studies did not confirm these observations [13, 14], and some even found a negative correlation between adiponectin and the severity of disease $[15,16]$. Some studies have described the association of serum adiponectin with radiographic features of RA progression $[17,18]$, but others have suggested a protective role of adiponectin in this respect [19]. Furthermore, it is not clear whether and how the levels of adiponectin are affected by treatment regimens for RA [20-22]. One may hypothesise that the role of adiponectin in RA changes over the course and stage

Correspondence: Dorota Sikorska, MD, PhD, Department of Rheumatology and Rehabilitation, Poznan University of Medical Sciences, 135/147 28 Czerwca 1956 St., 61-545 Poznan, Poland, e-mail: dorota_s8@wp.pl

Submitted: 5.04.2018; Accepted: 9.05.2018 
of the disease. In this respect, it has been demonstrated that serum levels of adiponectin increase with the disease duration. Moreover, it has been observed that there was a negative correlation between serum adiponectin and clinical activity of the disease in patients with long-lasting RA, but not in those with early disease [15].

In the present exploratory study, we have attempted to determine whether serum levels of adiponectin reflect somehow the clinical phenotype of RA patients and/or correlate with severity of the disease and the response to anti-TNF- $\alpha$ therapy.

\section{Material and methods}

\section{Patients}

Twenty-one consecutive Caucasian female patients starting anti-TNF- $\alpha$ therapy for RA were enrolled into the analysis. The study was confined to females because adipokine levels differ significantly between the sexes [7], and female patients made up the majority of our RA patient population. The inclusion criteria were as follows: 1) the diagnosis of RA according to the American-European Consensus Group classification criteria [23], 2) the unsuccessful treatment for RA with synthetic disease-modifying anti-rheumatic drugs (sDMARDs) according to the current guidelines [23-25]. Exclusion criteria were: 1 ) heart failure (NYHA class $\geq$ II), 2) respiratory, kidney, or liver failure, 3 ) an acute or oppor-

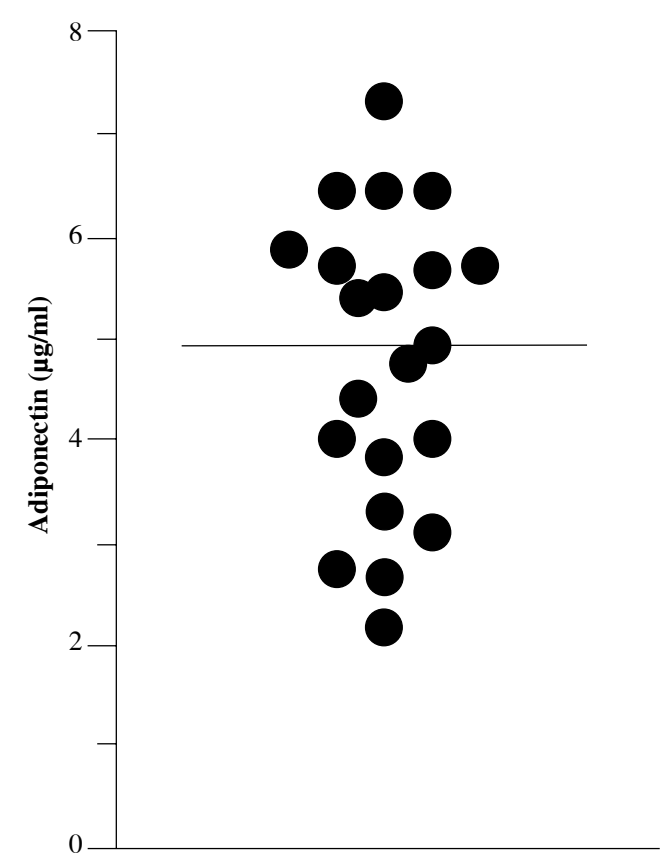

Fig. 1. Serum adiponectin levels in RA patients before the commencement of anti-TNF $\alpha$ therapy. The horizontal bar represents the median value tunistic infection in the last three months, 4) a documented HIV infection, 5) cancer (including a disease identified and cured in the past five years), 6) demyelinating diseases, and 7) pregnancy. The study protocol was approved by the Bioethics Committee of Poznan University of Medical Sciences (No. 1067/15), and written, informed consent was obtained from all participants.

\section{Treatment}

Patients received anti-TNF- $\alpha$ treatment (adalimumab, certolizumab, etanercept, golimumab, or infliximab) as per standard protocols [25]. Nine patients (43\%) continued to receive methotrexate, according to the European League Against Rheumatism (EULAR) recommendations [24, 25]; the 12 remaining patients did not tolerate methotrexate. In patients with severe symptoms, corticosteroids $(\leq 5 \mathrm{mg}$ prednisone/day) and non-steroid anti-inflammatory drugs (NSAIDs) were allowed, but such patients were included in the analysis only when these drugs were administered at the same doses for at least four weeks before and during the whole anti-TNF- $\alpha$ therapy.

\section{Assessment of disease activity}

Patients underwent full clinical and biochemical assessment before and after 12 weeks of anti-TNF- $\alpha$ therapy. Disease activity was assessed by the Modified Disease Activity Score (DAS), which includes different 28-joint counts and erythrocyte sedimentation rate (DAS2 $8_{\text {ESR }}$ ) [26]. The therapeutic response was according to the EULAR defined by the EULAR criteria [24].

\section{Laboratory analysis}

Blood samples were collected in a fasting state at the time of clinical examination. Serum obtained was aliquoted and stored at $-80^{\circ} \mathrm{C}$ until measured for adiponectin, leptin, and visfatin using DuoSet Immunoassay kits (R\&D Systems; Minneapolis, MN, USA), as per manufacturer's instructions. All other laboratory tests were performed routinely by the hospital central laboratory.

\section{Statistical analysis}

Statistical analysis was performed using STATISTICA 10.0 software (StatSoft Polska, Kraków, Poland). Because the data obtained did not consistently display a normal distribution (as assessed by the Shapiro-Wilk test), they were analysed with nonparametric statistics using the Wilcoxon test and the Mann-Whitney test for paired and unpaired data, respectively. Categorised data were analysed with the $\chi^{2}$ test. Correlations between variables were analysed with the Spearman's rank correlation coefficient. The data are presented as medians and interquartile ranges or as percentages, as appropriate. Differences were considered significant at $p<0.05$. 
Table 1. Characteristics of subgroups according to baseline serum adiponectin (ADPN) concentration

\begin{tabular}{|c|c|c|c|}
\hline & $\begin{array}{l}\text { ADPN at baseline } \\
\quad \leq \text { median } \\
\quad(n=11)\end{array}$ & $\begin{array}{c}\text { ADPN at baseline } \\
>\text { median } \\
(n=10)\end{array}$ & $p$ \\
\hline \multicolumn{4}{|c|}{ Demographic characteristics } \\
\hline Age, years & $53(39-60)$ & $61(50-66)$ & 0.217 \\
\hline Disease duration, years & $8(3-16)$ & $8(6-18)$ & 0.458 \\
\hline BMI, $\mathrm{kg} / \mathrm{m}^{2}$ & $24.7(22.8-28.1)$ & $23.1(21.8-23.2)$ & 0.307 \\
\hline \multicolumn{4}{|c|}{ Clinical parameters of rheumatoid arthritis activity } \\
\hline \multicolumn{4}{|l|}{ DAS28 } \\
\hline Before treatment & $5.3(5.0-6.0)$ & $5.9(4.5-6.4)$ & 0.860 \\
\hline After treatment & $3.6(3.1-4.5)^{* 1}$ & $3.6(2.8-4.0)^{* 2}$ & 0.526 \\
\hline Change & $-1.8(-2.1-[-0.7])$ & $-1.8(-3.0-[-1.5])$ & 0.460 \\
\hline Non-responders (based on DAS28), $n(\%)$ & $2(18)$ & $0(0)$ & 0.156 \\
\hline \multicolumn{4}{|l|}{ TEN28 } \\
\hline Before treatment & $10(7-18)$ & $8(7-11)$ & 0.477 \\
\hline After treatment & $2(1-4)^{* 3}$ & $2(1-3)^{* 4}$ & 0.857 \\
\hline Change & $-6(-10-[-4])$ & $-7(-10-[-4])$ & 0.971 \\
\hline \multicolumn{4}{|l|}{ SW28 } \\
\hline Before treatment & $5(3-7)$ & $6(5-9)$ & 0.436 \\
\hline After treatment & $0(0-4)^{* 5}$ & $2(0-6)^{* 6}$ & 0.303 \\
\hline Change & $-3(-6-[-2])$ & $-3(-7-[-1])$ & 0.971 \\
\hline \multicolumn{4}{|l|}{ VAS } \\
\hline Before treatment & $70(68-80)$ & $61(58-83)$ & 0.230 \\
\hline After treatment & $42(29-68)^{* 7}$ & $43(39-50)^{* 8}$ & 0.751 \\
\hline Change & $-30(-46-[-12])$ & $-22(-35-12)$ & 0.359 \\
\hline \multicolumn{4}{|c|}{ Laboratory parameters of rheumatoid arthritis activity } \\
\hline \multicolumn{4}{|l|}{ Erythrocyte sedimentation rate } \\
\hline Before treatment, $\mathrm{mm} / \mathrm{h}$ & $22(12-30)$ & $26(16-42)$ & 0.647 \\
\hline After treatment, $\mathrm{mm} / \mathrm{h}$ & $20(15-30)$ & $10(7-20)^{* 9}$ & 0.084 \\
\hline Change, $\mathrm{mm} / \mathrm{h}$ & $-5(-14-6)$ & $-10(-30-[-2])$ & 0.130 \\
\hline \multicolumn{4}{|l|}{ C-reactive protein } \\
\hline Before treatment, $\mathrm{mg} / \mathrm{l}$ & $6.2(2.3-19.4)$ & $8.8(1.9-15.8)$ & 0.915 \\
\hline After treatment, mg/l & $6.7(3.7-16.3)$ & $0.2(0.1-1.6)^{* 10}$ & 0.001 \\
\hline Change $\mathrm{mg} / \mathrm{l}$ & $-0.2(-10-6)$ & $-6.5(-15.7-[-1.8])$ & 0.130 \\
\hline \multicolumn{4}{|l|}{ Leukocytes } \\
\hline Before treatment, $10^{3} / \mu \mathrm{l}$ & $8.8(6.0-9.5)$ & $10.3(7.6-13.9)$ & 0.113 \\
\hline After treatment, $10^{3} / \mu \mathrm{l}$ & $7.9(6.8-8.8)$ & $9.3(6.6-11.2)$ & 0.324 \\
\hline Change, $10^{3} / \mu \mathrm{l}$ & $-1(-1.2-0.9)$ & $-1.1(-2.8-[-0.2])$ & 0.245 \\
\hline \multicolumn{4}{|l|}{ Neutrophils } \\
\hline Before treatment, $10^{3} / \mu \mathrm{l}$ & $4.8(3.4-6.3)$ & $6.8(4.2-9.2)$ & 0.170 \\
\hline After treatment, $10^{3} / \mu 1$ & $4.9(3.4-5.8)$ & $4.8(2.5-6.5)^{* 11}$ & 0.888 \\
\hline Change, $10^{3} / \mu \mathrm{l}$ & $-0.6(-1.2-0.6)$ & $-1.8(-3.9-[-0.8])$ & 0.038 \\
\hline
\end{tabular}


Table 1. Cont.

\begin{tabular}{|c|c|c|c|}
\hline & $\begin{array}{c}\text { ADPN at baseline } \\
\leq \text { median } \\
(n=11)\end{array}$ & $\begin{array}{c}\text { ADPN at baseline } \\
>\text { median } \\
(n=10)\end{array}$ & $p$ \\
\hline \multicolumn{4}{|l|}{ Lymphocytes } \\
\hline Before treatment, $10^{3} / \mu \mathrm{l}$ & $1.9(1.6-2.4)$ & $2.0(1.5-3.0)$ & 0.832 \\
\hline After treatment, $10^{3} / \mu 1$ & $2.1(1.6-2.4)$ & $2.8(2.2-3.6)$ & 0.016 \\
\hline Change, $10^{3} / \mu 1$ & $0.0(-0.1-0.1)$ & $0.7(0.0-1.6)$ & 0.090 \\
\hline \multicolumn{4}{|l|}{ Neutrophil-to-lymphocyte ratio } \\
\hline Before treatment & $2.1(1.6-3.6)$ & $2.9(2.3-5.8)$ & 0.275 \\
\hline After treatment & $2.3(1.6-3.4)$ & $1.5(0.9-2.5)^{* 12}$ & 0.084 \\
\hline Change & $-0.1(-0.5-0.6)$ & $-1.3(-4.4-[-0.3])$ & 0.026 \\
\hline \multicolumn{4}{|c|}{ Adipokines } \\
\hline \multicolumn{4}{|l|}{ Leptin } \\
\hline Before treatment, $\mathrm{pg} / \mathrm{ml}$ & $706(555-848)$ & $628(434-870)$ & 0.724 \\
\hline After treatment, $\mathrm{pg} / \mathrm{ml}$ & $641(557-904)$ & $644(605-762)$ & 0.860 \\
\hline Change, $\mathrm{pg} / \mathrm{ml}$ & $-36(-207-260)$ & $82(-161-231)$ & 0.549 \\
\hline \multicolumn{4}{|l|}{ Visfatin } \\
\hline Before treatment, $\mathrm{ng} / \mathrm{ml}$ & $75(56-98)$ & $77(68-94)$ & 0.762 \\
\hline After treatment, $\mathrm{ng} / \mathrm{ml}$ & $64(58-91)$ & $74(56-104)$ & 0.596 \\
\hline Change, $\mathrm{ng} / \mathrm{ml}$ & $0(-21-3)$ & $2(-12-10)$ & 0.698 \\
\hline
\end{tabular}

\section{Results}

Twenty-one consecutive patients qualified to receive anti-TNF- $\alpha$ therapy for RA were analysed. Baseline serum adiponectin concentration in this patient population was found to range from $2.24 \mu \mathrm{g} / \mathrm{ml}$ to $7.33 \mu \mathrm{g} / \mathrm{ml}$ (Fig. 1).

In order to assess whether concentrations of adiponectin characterise the patients' status, the individuals were divided into two subgroups according to whether their baseline serum adiponectin was below or above the median value $(4.95 \mu \mathrm{g} / \mathrm{ml})$. The patients thus stratified did not differ in basic demographic, anthropometric, and clinical parameters (Table 1).

Twelve weeks of anti-TNF- $\alpha$ treatment resulted in a significant clinical improvement (as assessed by DAS28, TEN28, SW28, and VAS indexes) in patients from both groups. Only two patients (10\%) were identified as EULAR non-responders, and they were found to belong to the subgroup with low baseline adiponectin. Nevertheless, this pattern of distribution did not yield a formal statistical significance ( $p=$ 0.156). Interestingly, however, patients with higher baseline adiponectin experienced a significant and a more pronounced improvement in several laboratory parameters of RA activity (ESR, CRP, neutrophil count, neutrophil-to-lymphocyte ratio) (Table 1). They achieved lower CRP values and a more favourable neutrophil-to-lymphocyte ratio after treatment
(Table 1). Interestingly, serum baseline adiponectin levels correlated with final CRP only in patients with RA duration $\geq 8$ years $(n=11 ; r=-0.79, p=0.003)$.

The levels of adiponectin did not change significantly within the groups following the treatment (Fig. 2A). Regarding other adipokines, leptin and visfatin did not differ between the groups either at baseline or after 12 weeks of anti-TNF- $\alpha$ therapy (Fig. 2B and Fig. 2C).

\section{Discussion}

The main observation of the present study was that RA patients with higher serum adiponectin experienced a more pronounced biochemical improvement in response to anti-TNF- $\alpha$ therapy compared with patients with lower adiponectin concentrations. This was reflected by a greater decrease in CRP, neutrophil counts, and ESR, together with a greater increase in lymphocyte counts. These effects seemed to be independent of classic clinical indices of RA activity, which improved in both groups to a similar extent. It is possible that adiponectin plays different roles in serum and in the synovial fluid [10]. In vitro studies have shown proinflammatory effects of adiponectin on chondrocytes and synoviocytes $[8,9]$, but serum adiponectin may still 

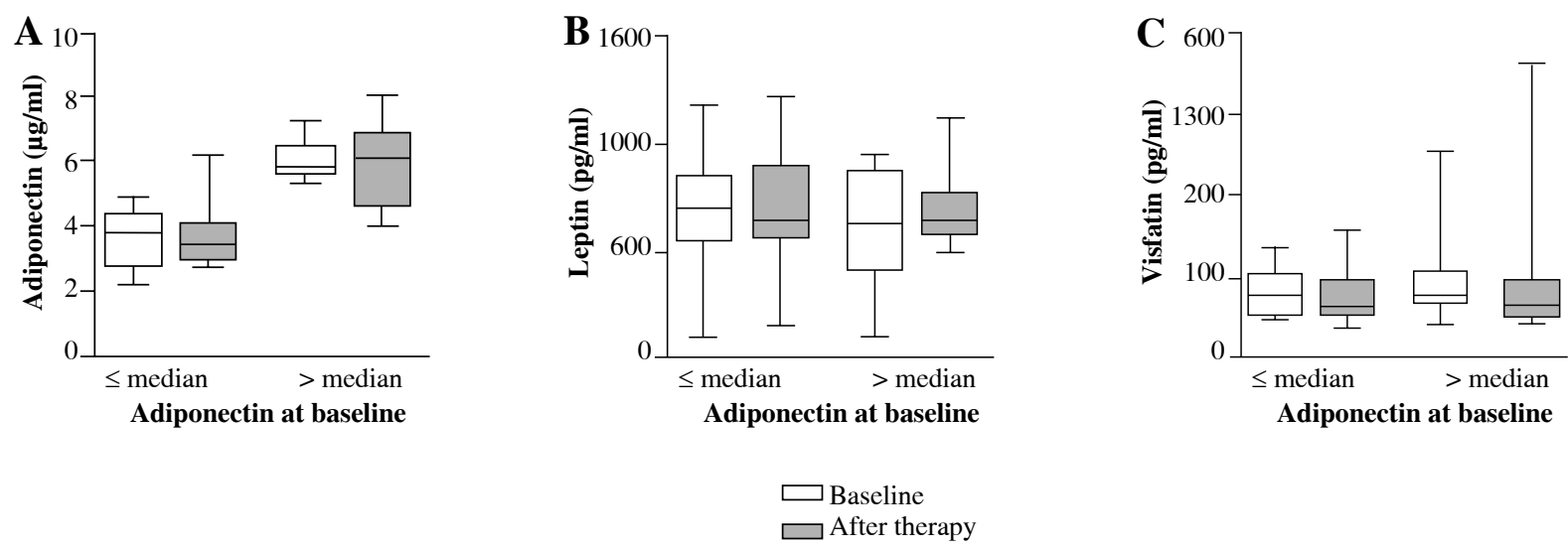

Fig. 2. Adiponectin, leptin, and visfatin levels before and after 12 weeks of anti-TNF $\alpha$ therapy in patients stratified at baseline according to adiponectin levels (as described in Methods). Boxes represent median values and interquartile ranges, and whiskers represent the ranges of values

have some systemic anti-inflammatory effects in patients with RA [27-29].

Previous studies assessing the association between adiponectin and other inflammatory biomarkers produced unequivocal results. A recent meta-analysis failed to demonstrate a significant correlation between serum levels of adiponectin and CRP [13]. However, some studies reported a clear relationship between circulating adiponectin and CRP [27]. Moreover, some [21, 30], but not all [22, 31 ], studies have demonstrated that anti-TNF- $\alpha$ therapy in RA was associated with an increase in serum adiponectin levels. A few studies suggested that the level of serum adiponectin in RA is related to disease duration [15, 32]. In this respect, we have observed that serum adiponectin levels correlated with CRP only in patients with RA duration $\geq 8$ years.

The net effect of adiponectin activity may depend on the proportions of low and high molecular weight isoforms [8]. In this respect, the proinflammatory activities of adiponectin are attributed to a high molecular weight isoform, whereas anti-inflammatory effects are thought to be exerted by low molecular adiponectin [33]. The immunoassay employed in the present study was designed to measure total (i.e. both low and high molecular weight) human adiponectin, Therefore, future studies will need to assess specifically the role of different adiponectin isoforms in RA.

Moreover, they will need to compare adipokine levels separately in female and male RA patients. This is because the sexes differ generally in the amount of adipose tissue and consequently in the magnitude of adipokine release $[7,27]$. In this respect, we have recently demonstrated that some changes in serum adipokine levels in obese patients occur in men but not in women [34]. Furthermore, it would be interesting to compare the levels of adiponectin in serum to those in the synovial fluids because it may discriminate between systemic and local adiponectin activities.
An obvious limitation of our study is the small number of patients analysed and the fact they were all treated in a single centre. Thus, our observations should be viewed as preliminary and should be validated in a much larger and heterogeneous independent patient population.

\section{Conclusions}

Patients with higher serum adiponectin experienced a more pronounced biochemical improvement in response to anti-TNF- $\alpha$ therapy, compared with patients with lower adiponectin concentrations. These effects seemed to be independent of classic clinical indices of RA activity.

\section{Acknowledgments}

The research reported herein was funded by a Poznan University of Medical Sciences Grant for Young Researchers.

The authors declare no conflict of interest.

\section{References}

1. Neumann E, Junker S, Schett G, et al. (2016): Adipokines in bone disease. Nat Rev Rheumatol 12: 296-302.

2. Liu D, Luo S, Li Z (2015): Multifaceted roles of adiponectin in rheumatoid arthritis. Int Immunopharmacol 28: 1084-1090.

3. Toussirot E, Michel F, Binda D, Dumoulin G (2015): The role of leptin in the pathophysiology of rheumatoid arthritis. Life Sci 140: 29-36.

4. Abella V, Scotece M, Conde J, et al. (2017): Leptin in the interplay of inflammation, metabolism and immune system disorders. Nat Rev Rheumatol 13: 100-109.

5. Muller-Ladner U, Neumann E. (2009): Rheumatoid arthritis: the multifaceted role of adiponectin in inflammatory joint disease. Nat Rev Rheumatol 5: 659-660. 
6. Chen X, Lu J, Bao J, et al. (2013): Adiponectin: a biomarker for rheumatoid arthritis? Cytokine Growth Factor Rev 24: 83-89.

7. Fasshauer M, Bluher M (2015): Adipokines in health and disease. Trends Pharmacol Sci 36: 461-470.

8. Scotece M, Conde J, Lopez V, et al. (2014): Adiponectin and leptin: new targets in inflammation. Basic Clin Pharmacol Toxicol 114: 97-102.

9. Ehling A, Schaffler A, Herfarth H, et al. (2006): The potential of adiponectin in driving arthritis. J Immunol 176: 4468-4478.

10. Senolt L, Pavelka K, Housa D, Haluzik M (2006): Increased adiponectin is negatively linked to the local inflammatory process in patients with rheumatoid arthritis. Cytokine 35 : 247-252.

11. Ozgen M, Koca SS, Dagli N, et al. (2010): Serum adiponectin and vaspin levels in rheumatoid arthritis. Arch Med Res 41: 457-463.

12. Alkady EA, Ahmed HM, Tag L, Abdou MA (2011): [Serum and synovial adiponectin, resistin, and visfatin levels in rheumatoid arthritis patients. Relation to disease activity]. Z Rheumatol 70: 602-608.

13. Lee YH, Bae SC (2018): Circulating adiponectin and visfatin levels in rheumatoid arthritis and their correlation with disease activity: A meta-analysis. Int J Rheum Dis 21: 664-672.

14. Cao H, Lin J, Chen W, et al. (2016): Baseline adiponectin and leptin levels in predicting an increased risk of disease activity in rheumatoid arthritis: A meta-analysis and systematic review. Autoimmunity 49: 547-553.

15. Targonska-Stepniak B, Dryglewska M, Majdan M (2010): Adiponectin and leptin serum concentrations in patients with rheumatoid arthritis. Rheumatol Int 30: 731-737.

16. Li P, Yang L, Ma CL, et al. (2015): Low-molecular-weight adiponectin is more closely associated with disease activity of rheumatoid arthritis than other adiponectin multimeric forms. Clin Rheumatol 34: 1025-1030.

17. Klein-Wieringa IR, van der Linden MP, Knevel R, et al. (2011): Baseline serum adipokine levels predict radiographic progression in early rheumatoid arthritis. Arthritis Rheum 63: 2567-2574.

18. Meyer M, Sellam J, Fellahi S, et al. (2013): Serum level of adiponectin is a surrogate independent biomarker of radiographic disease progression in early rheumatoid arthritis: results from the ESPOIR cohort. Arthritis Res Ther 15: R210.

19. Ibrahim SM, Hamdy MS, Amer N (2008): Plasma and synovial fluid adipocytokines in patients with rheumatoid arthritis and osteoarthritis. Egypt J Immunol 15: 159-170.

20. Klaasen R, Herenius MM, Wijbrandts CA, et al. (2012): Treatment-specific changes in circulating adipocytokines: a comparison between tumour necrosis factor blockade and glucocorticoid treatment for rheumatoid arthritis. Ann Rheum Dis 71: 1510-1516.

21. Engvall IL, Tengstrand B, Brismar K, Hafstrom I (2010): Infliximab therapy increases body fat mass in early rheumatoid arthritis independently of changes in disease activity and levels of leptin and adiponectin: a randomised study over 21 months. Arthritis Res Ther 12: R197.

22. Popa C, Netea MG, de Graaf J, et al. (2009): Circulating leptin and adiponectin concentrations during tumor necrosis factor blockade in patients with active rheumatoid arthritis. J Rheumatol 36: 724-730.
23. Aletaha D, Neogi T, Silman AJ, et al. (2010): rheumatoid arthritis classification criteria: an American College of Rheumatology/European League Against Rheumatism collaborative initiative. Ann Rheum Dis 69: 1580-1588.

24. van Gestel AM, Prevoo ML, van ,t Hof MA, et al. (1996): Development and validation of the European League Against Rheumatism response criteria for rheumatoid arthritis. Comparison with the preliminary American College of Rheumatology and the World Health Organization/International League Against Rheumatism Criteria. Arthritis Rheum 39: 34-40.

25. Smolen JS, Landewe R, Breedveld FC, et al. (2014): EULAR recommendations for the management of rheumatoid arthritis with synthetic and biological disease-modifying antirheumatic drugs: 2013 update. Ann Rheum Dis 73: 492-509.

26. Prevoo ML, van ,t Hof MA, Kuper HH, et al. (1995): Modified disease activity scores that include twenty-eight-joint counts. Development and validation in a prospective longitudinal study of patients with rheumatoid arthritis. Arthritis Rheum 38: 44-48.

27. Yoshino T, Kusunoki N, Tanaka N, et al. (2011): Elevated serum levels of resistin, leptin, and adiponectin are associated with C-reactive protein and also other clinical conditions in rheumatoid arthritis. Intern Med 50: 269-275.

28. Toussirot E, Binda D, Gueugnon C, Dumoulin G (2012): Adiponectin in autoimmune diseases. Curr Med Chem 19: 5474-5480.

29. Fantuzzi G (2008): Adiponectin and inflammation: consensus and controversy. J Allergy Clin Immunol 121: 326-330.

30. Kim KS, Choi HM, Ji HI, et al. (2014): Serum adipokine levels in rheumatoid arthritis patients and their contributions to the resistance to treatment. Mol Med Rep 9: 255-260.

31. Ferraz-Amaro I, Arce-Franco M, Muniz J, et al. (2011): Systemic blockade of TNF-alpha does not improve insulin resistance in humans. Horm Metab Res 43: 801-808.

32. Kontny E, Zielinska A, Ksiezopolska-Orlowska K, Gluszko $P$ (2016): Secretory activity of subcutaneous abdominal adipose tissue in male patients with rheumatoid arthritis and osteoarthritis - association with clinical and laboratory data. Reumatologia 54: 227-235.

33. Haugen F, Drevon CA (2007): Activation of nuclear factor-kappaB by high molecular weight and globular adiponectin. Endocrinology 148: 5478-5486.

34. Korybalska K, Swora-Cwynar E, Luczak J, et al. (2016): Association of endothelial proliferation with the magnitude of weight loss during calorie restriction. Angiogenesis 19: 407419. 